\title{
PERANCANGAN SISTEM STORAGE AND RETRIEVAL MACHINE PADA SIMULASI AUTOMATED STORAGE AND RETRIEVAL SYSTEM DENGAN MEMANFAATKAN ROBOTINO $^{\circledR}$
}

\author{
${ }^{1}$ Satya Wicaksana Mukhlisin, ${ }^{2}$ Haris Rachmat, ${ }^{3}$ Tatang Mulyana \\ 1,2,3 Program Studi Teknik Industri, Fakultas Rekayasa Industri, Universitas Telkom \\ ${ }^{1}$ satyaenong@gmail.com, ${ }^{2 h}$ haris.bdg23@gmail.com,3tatang21april@gmail.com
}

\begin{abstract}
Abstrak-Pengetahuan AS/RS dan S/R machine merupakan hal yang penting bagi mahasiswa Teknik Industri agar pada saat terjun di dunia pekerjaan, khususnya di aktivitas pergudangan, mahasiswa tersebut dapat mengaplikasikan ilmu tersebut untuk melakukan improvement dalam aktivitas pergudangan perusahaan. Terdapat tiga kebutuhan dasar dalam merancang Robotino ${ }^{\circledR}$ sebagai $\mathrm{S} / \mathrm{R}$ machine yaitu sistem rancangan, software, dan hardware. Untuk kebutuhan software adalah sistem operasi Windows 8 dan Robotino ${ }^{\circledR}$ View. Untuk kebutuhan hardware terdiri atas enam komponen yaitu komputer, Robotino ${ }^{\circledR}$, webcam, sensor induktif, baterai, dan gripper system. Akan tetapi, untuk pendukung skenarionya dibutuhkan empat komponen yaitu struktur akrilik, sensor trigger, solasi alumunium, dan item. Berdasarkan hasil pengujian, waktu untuk menyelesaikan seluruh proses adalah 647,1 detik. Berdasarkan hasil perhitungan dari simulasi finansial, NPV biaya kumulatif yang lebih kecil adalah alternatif kedua, yaitu dengan menggunakan satu operator dan satu Robotino ${ }^{\circledR}$, dengan nilai NPV kumulatif sebesar Rp16.657.138,00. Terdapat tujuh faktor yang perlu diperbaiki dari sistem yang dirancang yaitu pencahayaan, koneksi, baterai, jalur lintasan, gripper system, bahan pembuat slider, workstation, dan rak, serta umur mesin.
\end{abstract}

Kata kunci: AS/RS, proses penyimpanan, S/R machine, Robotino ${ }^{\circledR}$, Robotino ${ }^{\circledR}$ View, NPV biaya kumulatif

\section{PENDAHULUAN}

Saat ini terdapat sebuah sistem yang memanfaatkan teknologi otomasi untuk membantu aktivitas pergudangan, sistem tersebut adalah automated storage and retrieval system (AS/RS). AS/RS adalah sistem penyimpanan yang menjalankan operasi penyimpanan dan pengambilan item dengan kecepatan dan akurasi yang telah ditetapkan oleh derajat otomasi [1] [2] [3]. Dalam penggunaanya, AS/RS memiliki banyak manfaat dan kelebihan dibanding sistem yang tidak terotomatisasi [4]. Penggunaan AS/RS juga dapat menghemat biaya pekerja dan luas gudang, meningkatkan reliabilitas dan mengurangi error state dalam aktivitas pergudangan [5]. Dalam pengoperasiannya, salah satu komponen penyusun AS/RS adalah material handling atau pemindah barang. Banyak alternatif yang dapat digunakan sebagai AS/RS, salah satunya adalah $\mathrm{S} / \mathrm{R}$ machine menggunakan robot industri. Saat ini pemakaian robot dalam kegiatan industri semakin meningkat dibuktikan oleh grafik pada Gambar 1.

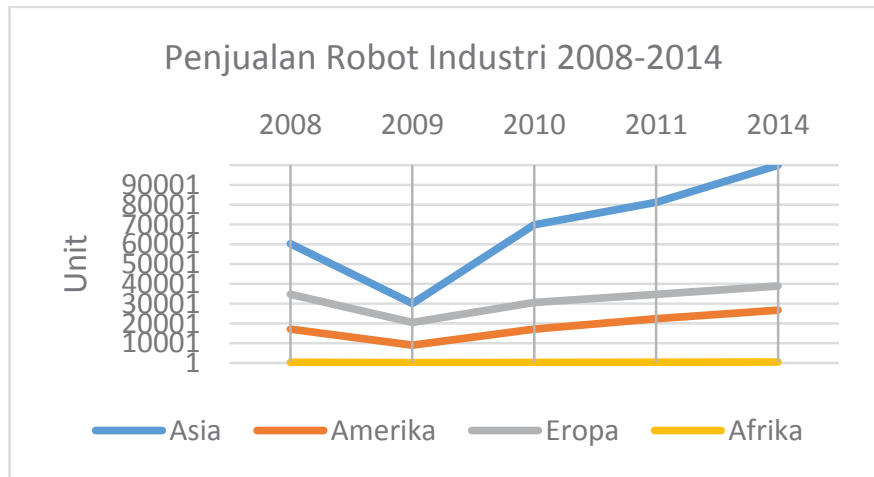

Gambar 1 Penjualan Robot Industri Tahun 2008 s.d. 2014 [6]

Gambar 1 menunjukkan grafik penjualan robot di empat wilayah. Semua wilayah mengalami peningkatan dalam penjualan robot industri dan Asia merupakan wilayah dengan tingkat penjualan tertinggi. Adanya peningkatan dalam penggunaan robot sebagai $\mathrm{S} / \mathrm{R}$ machine adalah karena robot memiliki daya tahan, konsistensi, dan akurasi yang lebih besar dibanding manusia. Pengetahuan AS/RS dan S/R machine merupakan hal yang penting bagi mahasiswa, khususnya mahasiswa Teknik Industri agar pada saat terjun di dunia pergudangan, mahasiswa tersebut dapat mengaplikasikannya untuk melakukan improvement dalam aktivitas pergudangan perusahaan. Robotino ${ }^{\circledR}$ merupakan robot yang diproduksi oleh Festo yang dikembangkan untuk tujuan edukasi, penelitian dan kompetisi [7] [8]. Kemudian berdasarkan Festo, Robotino ${ }^{\circledR}$ dapat dirancang untuk kebutuhan penelitian dan edukasi. Oleh karena itu, penelitian ini membahas perancangan Robotino ${ }^{\circledR}$ sebagai S/R machine dan menyimulasikannya dalam sebuah simulasi AS/RS. Dari integrasi penelitian ini, diharapkan tercipta simulasi AS/RS yang dapat meningkatkan pengetahuan di bidang otomatisasi sistem penyimpanan dan pengambilan item di pergudangan. 


\section{PERANCANGAN SISTEM}

Proses penyimpanan adalah proses terakhir yang dijalankan setelah proses penyortiran item dan proses pemindahan item ke workstation telah selesai dijalankan. Proses penyimpanan dimulai pada saat semua item telah berada di workstation masing-masing. Tugas utama dari proses penyimpanan ini adalah untuk membawa item yang ada di workstation ke tempat penyimpanan atau rak sesuai dengan warnanya masing-masing. Gambar 2 menunjukkan rancangan arena pada skenario AS/RS. Skenario ini berawal dari proses sortir item sampai penyimpanan item. Kemudian Gambar 1 terdiri atas beberapa kode yang diterangkan pada Tabel I.

Secara garis besar, urutan proses dari proses penyimpanan disusun menjadi sembilan proses utama. Perbedaan yang mendasari setiap proses adalah letak workstation untuk pengambilan item dan letak rak untuk penyimpanan item. Untuk jenis kegiatan yang pada setiap proses utama tidak berbeda, hal ini karena Robotino ${ }^{\circledR}$ menggunakan jalur yang sama dan pada penelitian ini menggunakan jenis workstation dan rak yang sama sehingga Robotino $^{\circledR}$ hanya perlu menjalankan satu jenis kegiatan untuk setiap pengambilan dan penyimpanan. Kemudian jumlah sensor jarak yang digunakan untuk setiap proses utama adalah sama sebanyak lima buah, yaitu IR1, IR2, IR3, IR8, dan IR9. Untuk IR1, IR3, dan IR8 digunakan untuk melakukan gerakan maju, mundur, dan memutar. Kemudian IR2 dan IR9 digunakan untuk melakukan balancing pada saat Robotino ${ }^{\circledR}$ bergerak. Tidak semua sensor digunakan pada proses yang dirancang. Ini disebabkan semakin banyak sensor yang digunakan maka akan semakin rumit pemrogramannya juga dengan jumlah sensor yang digunakan, proses sudah bisa dijalankan sehingga tidak semua sensor harus digunakan.

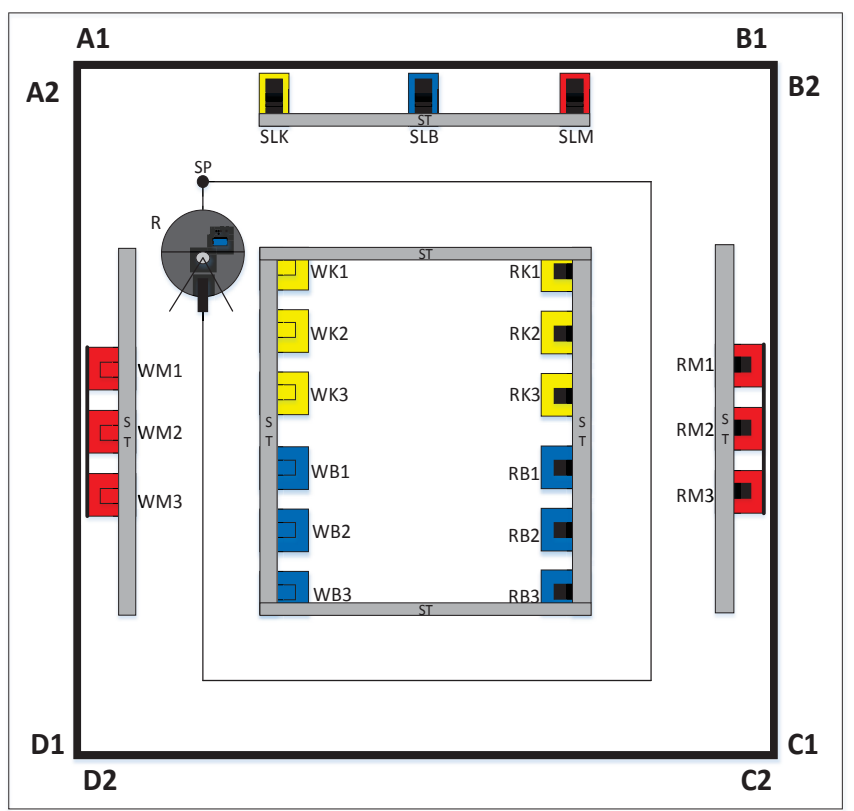

Gambar 2 Perancangan Arena dan Skenario Storage System
TABEL I

KETERANGAN LAMBANG

\begin{tabular}{|l|l|}
\hline Kode & Pengertian \\
\hline SP & Start Point \\
\hline R & Robotino ${ }^{\circledR}$ \\
\hline A1 & Sudut Kiri Atas untuk Berputar CW \\
\hline A2 & Sudut Kiri Atas untuk Berputar CCW \\
\hline B1 & Sudut Kanan Atas untuk Berputar CCW \\
\hline B2 & Sudut Kanan Atas untuk Berputar CW \\
\hline C1 & Sudut Kanan Bawah untuk Berputar CCW \\
\hline C2 & Sudut Kanan Bawah untuk Berputar CW \\
\hline D1 & Sudut Kiri Bawah untuk Berputar CW \\
\hline D2 & Sudut Kiri Bawah untuk Berputar CCW \\
\hline ST & Sensor Trigger \\
\hline WM1/2/3 & Workstation Merah $1 / 2 / 3$ \\
\hline WB1/2/3 & Workstation Biru $1 / 2 / 3$ \\
\hline WK1/2/3 & Workstation Kuning $1 / 2 / 3$ \\
\hline RM1/2/3 & Rak Merah $1 / 2 / 3$ \\
\hline RB1/2/3 & Rak Biru $1 / 2 / 3$ \\
\hline RK1/2/3 & Rak Kuning $1 / 2 / 3$ \\
\hline
\end{tabular}

Agar sistem perdana tersebut dapat diimplementasikan dengan sempurna, sistem tersebut akan dirancang dengan memerhatikan beberapa parameter sebagai berikut.

1. Rak penyimpanan yang akan dirancang adalah rak sebanyak tiga buah dengan setiap rak memiliki tiga bay. Rancangan tersebut dibuat berdasarkan pertimbangan jumlah item yang akan disimpan pada saat mendemonstrasikan sistem tersebut.

2. Sistem penyimpanan yang diterapkan adalah setiap pigeon hole terdiri atas satu item, dan urutan penyimpanannya adalah diisi yang paling dekat dengan posisi awal robot terlebih dahulu.

3. Jalur lintasan terbuat dari solasi alumunium yang dapat dibaca oleh sensor induktif pada Robotino ${ }^{\circledR}$.

Sistem baru yang akan dirancang ini membutuhkan perangkat lunak (software) untuk mengendalikan Robotino ${ }^{\circledR}$ sebagai $\mathrm{S} / \mathrm{R}$ machine dalam melakukan proses penyimpanan item ke dalam rak. Software yang diperlukan adalah sebagai berikut.

1. Sistem operasi Windows 8, software ini diperlukan untuk menjalankan operasi yang ada di komputer secara keseluruhan.

2. Robotino $^{\circledR}$ View, software ini digunakan sebagai jembatan komunikasi antara komputer dengan S/R machine yang terbuat dari Robotino ${ }^{\circledR}$.

Perancangan Robotino ${ }^{\circledR}$ sebagai S/R machine ini juga membutuhkan perangkat keras (hardware) sebagai komponen fisik pembentuk S/R machine. Berikut ini merupakan sembilan hardware yang diperlukan untuk membangun $\mathrm{S} / \mathrm{R}$ machine.

1. Komputer, digunakan untuk membuat rangkaian program storage system melalui software Robotino ${ }^{\circledR}$ View.

2. Robotino ${ }^{\circledR}$, adalah robot yang digunakan untuk menjalankan program storage system. Robot ini dilengkapi dengan satu buah sensor anti-collision, sembilan buah sensor proximity, satu buah sensor induktif, dua buah sensor optik, dan satu buah webcam Logitech. 
3. Webcam, merupakan bagian dari Robotino ${ }^{\circledR}$ yang digunakan untuk menditeksi keberadaan item dan mengidentifikasi warna dari item yang akan dibawa.

4. Sensor Induktif, merupakan bagian dari Robotino ${ }^{\circledR}$ yang digunakan untuk membaca solasi alumunium sebagai jalur bagi Robotino ${ }^{\circledR}$ untuk berjalan.

5. Power supply / baterai kering, merupakan sumber energi yang dibutuhkan oleh Robotino ${ }^{\circledR}$ agar dapat berfungsi.

6. Gripper system, adalah sistem perangkat keras yang berfungsi mengambil dan meletakkan item sesuai program yang dibuat. Sistem ini terbagi menjadi dua bagian besar.

a. Gripper, merupakan pencapit yang dipasang pada Robotino $^{\circledR}$ untuk membawa item dan menyimpan item dari satu tempat ke tempat yang lain.

b. Servo, merupakan motor DC yang digunakan untuk menggerakkan gripper. Servo tersebut dikendalikan oleh sebuah sistem pengendali yang dinamakan servo driver.

c. Servo driver, merupakan sistem pengendali yang dihubungkan dengan I/O port pada Robotino ${ }^{\circledR}$. Hardware ini memberikan perintah kepada servo untuk menggerakkan gripper.

d. Struktur, merupakan plat logam yang dipasangkan pada Robotino ${ }^{\circledR}$ yang berfungsi sebagai tempat penyangga gripper, servo, dan servo driver.

Selanjutnya untuk mendukung skenario proses penyimpanan, terdapat empat kebutuhan perangkat keras yang dijelaskan sebagai berikut.

1. Struktur akrilik, merupakan plat akrilik yang didesain untuk menjadi model workstation dan rak. Untuk workstation dan rak memiliki desain dan ukuran yang sama. Perbedaannya adalah pada penempatannya seperti yang sudah ditunjukkan pada Gambar 2 .

2. Sensor trigger, merupakan benda yang berfungsi sebagai pemicu sensor jarak yang ada pada Robotino ${ }^{\circledR}$ untuk membaca jarak benda yang ada di sekeliling Robotino ${ }^{\circledR}$. Pada penelitian ini, sensor trigger juga dirancang untuk mempermudah Robotino ${ }^{\circledR}$ dalam melakukan balancing ketika bergerak sehingga Robotino ${ }^{\circledR}$ tidak menabrak workstation atau rak.

3. Solasi alumunium, digunakan untuk membuat lintasan pada arena. Jalur ini akan dibaca oleh sensor induktif pada Robotino $^{\circledR}$. Tujuan dari penggunaan solasi ini adalah agar robot bergerak presisi sesuai dengan lintasan sehingga dapat terhindar dari salah arah atau tabrakan.

4. Item, merupakan balok yang terdiri atas tiga warna yaitu merah, biru dan kuning dengan jumlah yang sama yaitu tiga buah untuk setiap warna. Item ini diasumsikan sebagai item yang akan dibawa dan disimpan oleh Robotino $^{\circledR}$.

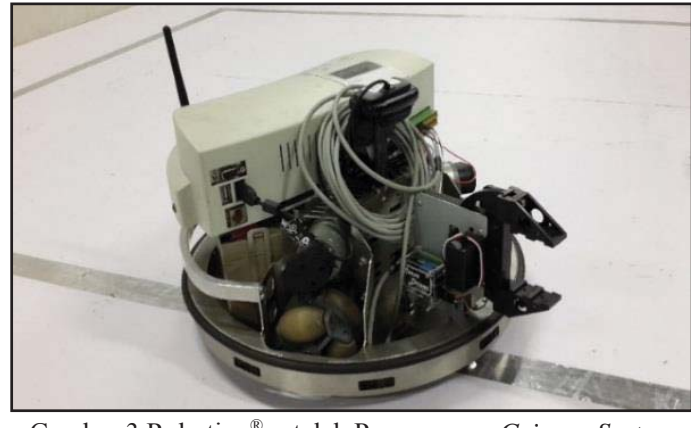

Gambar 3 Robotino ${ }^{\circledR}$ setelah Pemasangan Gripper System

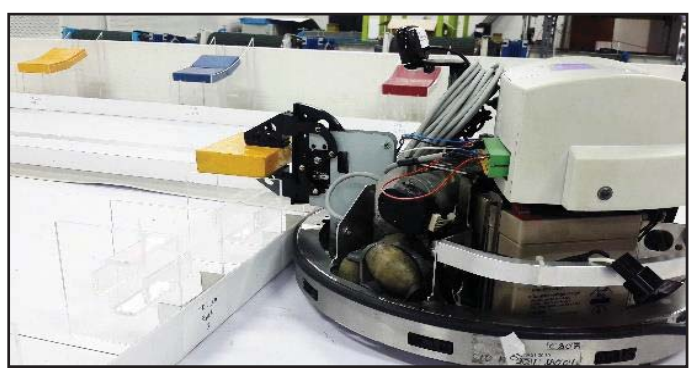

Gambar 4 Proses Pengambilan Item

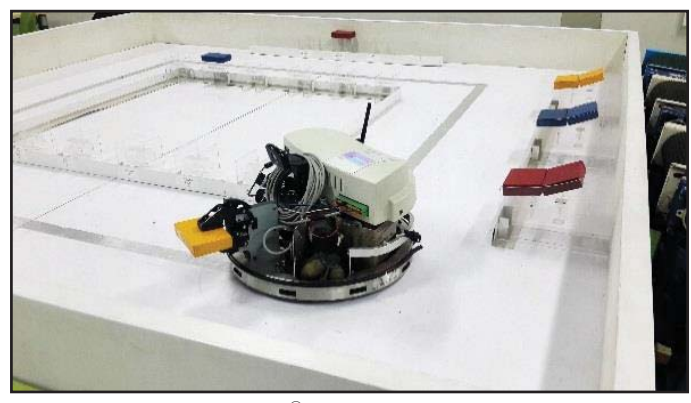

Gambar 5 Robotino ${ }^{\circledR}$ Membawa Item Menuju Rak

\section{ANALISIS}

Berikut merupakan rekapan keseluruhan dari waktu untuk setiap proses utama yang ditunjukkan oleh Tabel II. Berdasarkan perhitungan di atas disimpulkan bahwa waktu yang diperlukan untuk menyelesaikan sembilan proses utama adalah selama 647,1 detik. Kemudian berikut merupakan grafik yang ditunjukkan oleh Gambar 6 mengenai waktu yang telah direkap untuk setiap proses.

Berdasarkan grafik pada Gambar 6, disimpulkan bahwa proses yang paling lama adalah proses utama 6 yaitu selama 83,3 detik. Ini disebabkan karena proses utama ini menempuh jarak terjauh sehingga membutuhkan waktu yang lebih lama dibandingkan proses utama yang lain.

Setelah itu dilakukan simulasi finansial untuk mengetahui kelayakan dari simulasi yang telah dirancang. Karena ini merupakan simulasi, maka terdapat enam asumsi yang ditetapkan untuk membatasi simulasi yang telah dibuat. Kemudian berikut ini merupakan data yang dipakai pada simulasi ini untuk dijadikan sebagai acuan atau asumsi. 
TABEL II

REKAPAN WAKTU

\begin{tabular}{|c|c|}
\hline Proses Utama & Waktu (detik) \\
\hline 1 & 45,4 \\
\hline 2 & 70,7 \\
\hline 3 & 77,5 \\
\hline 4 & 75,9 \\
\hline 5 & 78,2 \\
\hline 6 & 83,3 \\
\hline 7 & 67,9 \\
\hline 8 & 70,7 \\
\hline 9 & 77,5 \\
\hline Total & 647,1 \\
\hline
\end{tabular}

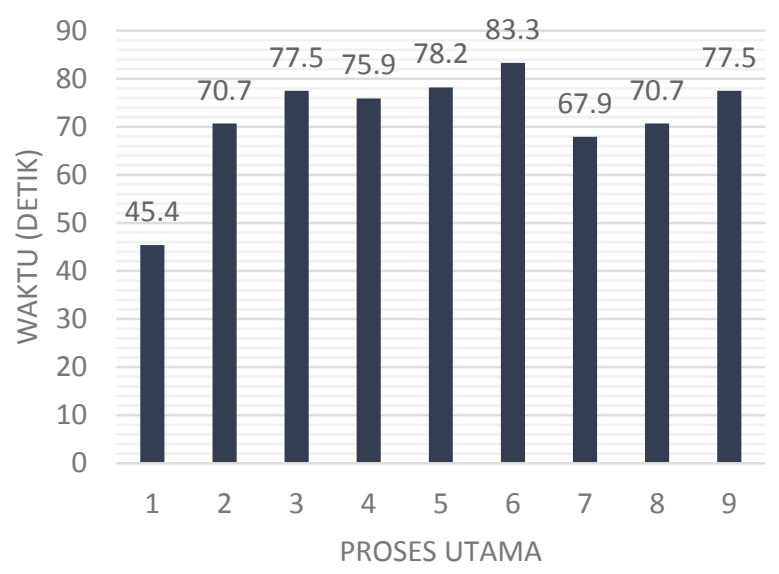

Gambar 6 Grafik Rekap Nilai

1. Analisis finansial ini menggunakan metode NPV (Net Present Value). Pada penelitian ini, NPV yang dihitung adalah NPV kumulatif untuk biaya operasional. Alternatif yang dipilih adalah alternatif yang memiliki NPV kumulatif biaya yang paling kecil.

2. Komponen yang dihitung pada simulasi ini adalah hanya biaya investasi / instalasi awal dan biaya operasional. Biaya operasional yang dihitung adalah upah pegawai, biaya maintenance, beban depresiasi dan biaya listrik. Sedangkan biaya investasi yang dihitung adalah biaya pada saat instalasi gripper system pada Robotino ${ }^{\circledR}$.

3. Baik alternatif pertama maupun kedua mempunyai kapasitas yang sama sehingga jumlah item yang disimpan untuk kedua alternatif adalah sama.

4. Semua operator pada kedua alternatif mempunyai upah yang standar yaitu mengacu pada UMR (Upah Minimum Regional).

5. Setiap hari terdapat lima puluh pengulangan dalam proses penyimpanan. Jumlah item yang disimpan untuk setiap pengulangan adalah sama yaitu sebanyak tiga item untuk setiap warna.

6. Pada alternatif kedua, biaya instalasi hanya biaya pemasangan gripper system (diasumsikan pada periode awal sudah memiliki Robotino ${ }^{\circledR}$ ) dan hanya dikeluarkan sekali pada saat tahun awal sebelum produksi.
TABEL III

DATA SIMULASI FINANSIAL

\begin{tabular}{|c|c|c|}
\hline \multicolumn{3}{|l|}{ Data Finansial } \\
\hline Data & Nilai & Sumber / Keterangan \\
\hline $\begin{array}{l}\text { UMR Kabupaten } \\
\text { Bandung }\end{array}$ & Rp 2.041.000,00 / bulan & $\begin{array}{l}\text { Keputusan Gubernur } \\
\text { Jawa Barat No. 561/Kep. } \\
\text { 1581-Bangsos/2014 }\end{array}$ \\
\hline Suku Bunga Bank & $7.50 \%$ & www.bi.go.id \\
\hline Rencana Evaluasi & 5 Tahun & Tahun 2016-2020 \\
\hline $\begin{array}{l}\text { Depresiasi } \\
\text { Hardware }\end{array}$ & 5 Tahun & $\begin{array}{l}\text { Straight Line } \\
\text { Depreciation }\end{array}$ \\
\hline Biaya Listrik & $\mathrm{Rp} 1.200,65 / \mathrm{kWh}$ & $\begin{array}{l}\text { Tariff Adjusment PLN } \\
\text { Juni } 2015 \text { untuk } \\
\text { Golongan I-3/TM }\end{array}$ \\
\hline $\begin{array}{l}\text { Pemakaian Daya } \\
\text { Charger } \\
\text { Robotino }^{\circledR}\end{array}$ & $56 \mathrm{Watt} /$ detik & Keterangan pada charger \\
\hline $\begin{array}{l}\text { Jumlah Hari Kerja } \\
\text { per Tahun }\end{array}$ & 308 hari & 360 Hari - 52 Minggu \\
\hline $\begin{array}{l}\text { Biaya } \\
\text { Maintenance } \\
\text { Robotino }^{\circledR}\end{array}$ & Rp 1.000.000,00 / tahun & $\begin{array}{l}\text { Biaya membersihkan } \\
\text { Robotino, perbaikan dan } \\
\text { penggantian baterai }\end{array}$ \\
\hline
\end{tabular}

TABEL IV

HASIL PERHITUNGAN NPV Biaya KUMULATIF

\begin{tabular}{|l|l|l|}
\hline \multirow{2}{*}{ Tahun } & \multicolumn{2}{|l|}{ NPV Biaya Kumulatif } \\
\cline { 2 - 3 } & Alternatif Pertama & Alternatif Kedua \\
\hline 2015 & $\mathrm{Rp}-$ & $\mathrm{Rp} \mathrm{927,600}$ \\
\hline 2016 & $\mathrm{Rp} \mathrm{3,797,209}$ & $\mathrm{Rp} \mathrm{4,095,966}$ \\
\hline 2017 & $\mathrm{Rp} \mathrm{7,594,419}$ & $\mathrm{Rp} \mathrm{7,252,291}$ \\
\hline 2018 & $\mathrm{Rp} 11,391,628$ & $\mathrm{Rp} \mathrm{10,397,417}$ \\
\hline 2019 & $\mathrm{Rp} \mathrm{15,188,837}$ & $\mathrm{Rp} \mathrm{13,532,123}$ \\
\hline 2020 & $\mathrm{Rp} \mathrm{18,986,047}$ & $\mathrm{Rp} \mathrm{16,657,138}$ \\
\hline
\end{tabular}

Setelah dilakukan perhitungan finansial (perhitungan selengkapnya terdapat pada Lampiran), diperoleh hasil NPV Biaya Kumulatif untuk kedua alternatif yang ditunjukkan pada Tabel IV. Kemudian dari hasil perhitungan tersebut dibuat grafik NPV biaya kumulatif untuk kedua alternatif yang ditunjukkan pada Gambar 7. Berdasarkan grafik di atas, berdasarkan hasil perhitungan simulasi finansial dengan mengacu pada asumsi yang telah ditetapkan, maka NPV biaya kumulatif yang lebih kecil adalah alternatif kedua yaitu sebesar Rp16.657.138,00. Oleh karena itu, dapat disimpulkan bahwa alternatif kedua lebih layak untuk dioperasikan yaitu dengan menggunakan satu operator dan satu buah Robotino ${ }^{\circledR}$. 


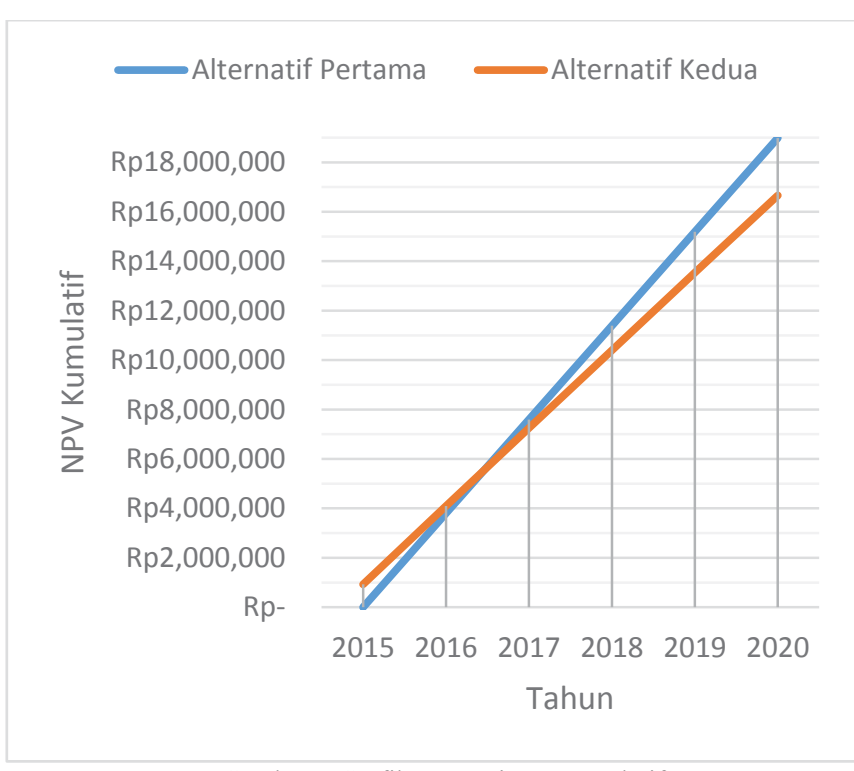

Gambar 7 Grafik NPV Biaya Kumulatif

\section{ANALISIS HAMBATAN PERFORMANSI ROBOTINO ${ }^{\circledR}$ SEBAGAI S/R MACHINE}

Berdasarkan hasil pengujian, terdapat tujuh faktor yang menjadi hambatan bagi Robotino ${ }^{\circledR}$ untuk bertindak sebagai S/R machine yaitu sebagai berikut.

1. Pencahayaan, merupakan faktor yang mempengaruhi kinerja webcam dalam mengolah warna objek yang akan diambil. Pada saat pencahayaan berubah, maka nilai HSV (Hue, Saturation, dan Value) yang terbaca pun akan berubah sehingga membuat webcam menjadi tidak dapat membaca keberadaan dan warna item. Solusi untuk hambatan ini adalah menjaga tingkat pencahayaan pada arena dengan cara menerangi arena dengan lampu. Solusi lainnya adalah dengan melakukan percobaan pada waktu yang sama pada saat pengambilan nilai HSV pada item.

2. Koneksi, pada saat Robotino ${ }^{\circledR}$ terhubung dengan komputer melalui wifi, sering adanya gangguan atau interferensi yang disebut wifi noise. Setiap komputer pun memiliki noise yang berbeda, tergantung dari performansinya. Gangguan ini merupakan sesuatu yang tidak dapat dihindarkan namun dapat diminimalisasi dengan cara memilih komputer dengan spesifikasi yang memadai dengan kualitas pemancar wifi yang baik sehingga noise yang diterima dapat diminimalisasi.

3. Baterai, merupakan faktor yang menjadi hambatan daya tahan Robotino $^{\circledR}$ dalam menjalankan program dari komputer. Apabila Robotino ${ }^{\circledR}$ menggunakan baterai yang kurang baik, maka Robotino ${ }^{\circledR}$ sulit untuk menuntaskan program (biasanya sudah habis daya sebelum program berakhir) dan waktu pengisian lebih lama dibanding dengan waktu nyalanya Robotino ${ }^{\circledR}$ itu sendiri. Pada penelitian ini, baterai yang digunakan merupakan baterai dengan kondisi yang kurang baik. Ini ditandai dengan lama pengisian daya yang lebih lama ketimbang waktu pemakaiannya (rata-rata lama pengisian daya pada baterai ini adalah 1,4 jam sedangkan lama pemakaiannya adalah
1,2 jam). Solusi dari hambatan ini adalah dengan mengganti baterai dengan baterai dengan kondisi yang lebih baik.

4. Jalur lintasan, penelitian ini menggunakan solasi alumunium sebagai lajur lintasan bagi Robotino ${ }^{\circledR}$. Oleh karena itu, Robotino ${ }^{\circledR}$ menggunakan sensor induktif untuk membaca lintasan yang terbuat dari solasi alumunium tersebut. Masalah adalah sensor induktif tidak dapat membaca persimpangan. Benda tersebut hanya menampilan ouput ada dan tidak saja (tidak analog) sehingga terkadang Robotino ${ }^{\circledR}$ harus melenceng dahulu baru setelah itu mencari dengan bantuan program. Solusinya adalah dengan menyesuaikan posisi Robotino ${ }^{\circledR}$ dengan baik dan benar pada saat di start point, menggunakan bantuan sensor jarak untuk balancing, dan membuat program pencarian jalur pada saat sensor induktif kehilangan jalur.

5. Gripper system, merupakan komponen yang sangat penting bagi Robotino ${ }^{\circledR}$ untuk dapat beroperasi sebagai $S / R$ machine. Namun terdapat hambatan yang teridentifikasi pada komponen ini. Hambatan pertama adalah grip yang terbuat dari bahan pelastik sehingga item tidak dapat digenggam erat karena permukaan yang licin. Solusi untuk hambatan tersebut adalah dengan cara menambahkan bahan yang kasar di permukaan grip. Kemudian hambatan lainnya adalah posisi gripper yang tidak sesuai dengan jarak baca sensor 1 sehingga pada saat aktivitas mengambil atau melepas, gripper tidak dapat berfungsi dengan baik dan membuat item terjatuh. Solusi untuk masalah tersebut adalah dengan menggunakan timer pada saat maju sebelum mengambil atau melepaskan item sehingga mendapatkan jarak yang sesuai dengan keinginan.

6. Bahan pembuat slider, workstation, dan rak. Pada penelitian ini, slider, workstation, dan rak terbuat dari bahan akrilik. Bahan ini mirip seperti kaca. Sensor jarak yang dimiliki oleh Robotino ${ }^{\circledR}$ adalah sensor beam yang mengeluarkan infrared untuk membaca jarak benda dengan Robotino ${ }^{\circledR}$. Ketika infrared tersebut mengenai bahan akrilik, maka infrared tersebut akan dipantulkan oleh akrilik sehingga nilai yang dihasilkan dapat berbedabeda tergantung pantulan yang dihasilkan. Solusi dari masalah ini adalah dengan mendesain ulang slider, workstation, dan rak dengan menempelkan bagian yang terkena infrared sensor dengan bahan yang tidak memantulkan cahaya (contohnya karton atau dupleks) sehingga sensor dapat membaca keberadaan benda dengan lebih jelas.

7. Umur mesin, merupakan faktor yang berasal dari Robotino $^{\circledR}$ yang juga memengaruhi kinerja Robotino ${ }^{\circledR}$ sebagai S/R machine. Faktor ini mempengaruhi beberapa komponen pada Robotino ${ }^{\circledR}$ diantaranya adalah omnidirectional drive dan wireless LAN access point. Omnidirectional drive akan kotor dan mengalami kausan jika sudah lama digunakan sehingga mengganggu gerakan Robotino ${ }^{\circledR}$. Solusi dari hambatan tersebut adalah dengan melakukan perawatan secara rutin terhadap Robotino ${ }^{\circledR}$ contohnya dengan membersihkan roda Robotino ${ }^{\circledR}$ dari 
debu dan kotoran atau dengan cara membersihkan arena tempat Robotino ${ }^{\circledR}$ bergerak. Hambatan lainnya adalah pada saat mesin telah lama digunakan, wireless LAN access point sering terputus koneksinya dengan komputer sehingga program menjadi terhenti. Solusi dari masalah tersebut adalah dengan memperbaiki wireless LAN access point sehingga memperbaiki kemampuan koneksi dengan komputer.

\section{KESIMPULAN}

Dari hasil analisis yang telah dilakukan, diperoleh kesimpulan yang menjawab tujuan dari penelitian ini yaitu sebagai berikut.

1. Dari simulasi proses penyimpanan yang dirancang, terdapat sembilan proses utama yang dibedakan berdasarkan lokasi workstation tempat pengambilan item dan lokasi rak tempat penyimpanan item. Lalu terdapat lima sensor jarak yang digunakan yaitu IR1, IR2, IR3, IR8, dan IR9. Kemudian terdapat tiga kebutuhan dasar dalam merancang Robotino ${ }^{\circledR}$ sebagai S/R machine yaitu kebutuhan sistem rancangan, kebutuhan software dan kebutuhan hardware. Untuk kebutuhan software adalah sistem operasi Windows 8 dan Robotino ${ }^{\circledR}$ View sebagai jembatan komunikasi antara komputer dengan Robotino ${ }^{\circledR}$. Lalu untuk kebutuhan hardware terdiri atas enam komponen yaitu komputer, Robotino ${ }^{\circledR}$, webcam, sensor induktif, baterai, dan gripper system. Sedangkan untuk pendukung skenarionya dibutuhkan empat komponen yaitu struktur akrilik, sensor trigger, solasi alumunium, dan item.

2. Pengujian dilakukan per step pada Robotino ${ }^{\circledR}$ View dengan memperhatikan hasil yang diharapkan dan parameter kuatitatif untuk setiap jenis kegiatan pada proses utama. Berdasarkan hasil pengujian didapatkan hasil bahwa keseluruhan proses berhasil dengan total waktu selama 647,1 detik

3. Berdasarkan pengujian terhadap setiap pengujian, maka dapat disimpulkan bahwa proses yang paling lama adalah proses utama 6 selama 83,3 detik. Hal ini disebabkan proses utama menempuh jarak terjauh sehingga membutuhkan waktu yang lebih lama dibandingkan proses utama yang lain.

4. Berdasarkan hasil perhitungan simulasi finansial dengan mengacu pada asumsi yang telah ditetapkan, maka NPV biaya kumulatif yang lebih kecil adalah alternatif kedua yaitu sebesar Rp16.657.138,00. Oleh karena itu, dapat disimpulkan bahwa alternatif kedua lebih layak untuk dioperasikan yaitu dengan menggunakan satu operator dan satu buah Robotino ${ }^{\circledR}$.

5. Berdasarkan hasil pengujian, terdapat tujuh faktor yang perlu diperbaiki dari sistem yang telah dirancang yaitu pencahayaan, koneksi, baterai, jalur lintasan, gripper system, bahan pembuat slider, workstation, dan rak, serta umur mesin

\section{DAFTAR PUSTAKA}

[1] Groover, M. P. Automation, Production Systems, and Computer Integrated Manufacture - Second Edition. John Wiley \& Sons. (2001).

[2] Groover, M. P. Otomasi, Sistem Produksi, dan Computer Integrated Manufacturing. Surabaya: Guna Widya. (2005).

[3] Groover, M. P. Fundamentals of Modern Manufacturing Fourth Edition. Wiley \& Sons. (2010).

[4] Roodbergen, K., \& Iris, F. A Survey of Literature on Automated Storage and Retrieval Systems. Science Direct, 1. (2008).

[5] Zollinger, H. "AS/RS Application, Benefits and Justification in Comparison to Other Storage Methods: A White Paper. Automated Storage Retrieval Systems Production Section of the Material Handling Industry of America”. Science Direct. (1999).

[6] Struijk, B. Robot Production Volume Data Trends and Analysis. (2012).

[7] Festo. (2014, 12). Diambil kembali dari www.fesodidactic.com.

[8] Festo. Festo Didactic - Robotino. Dipetik Desember 21, 2014, dari http://www.festo-didactic.com/(2014). 